\title{
Metabolic Alkalosis, Acute Renal Failure and Epileptic Seizures as Unusual Manifestations of an Upside-Down Stomach
}

\author{
Johannes Stephani $^{\mathrm{a}} \quad$ Martin Wagner $^{\mathrm{a}} \quad$ Thomas Breining $^{\mathrm{b}}$ \\ Jochen Klaus ${ }^{\mathrm{a}}$ Jan-Hendrik Niess ${ }^{\mathrm{a}}$ \\ Departments of ${ }^{\mathrm{a}}$ Internal Medicine I and ${ }^{\mathrm{b}}$ Diagnostic and Interventional \\ Radiology, Ulm University, Ulm, Germany
}

\section{Key Words}

Upside-down stomach $\cdot$ Hiatal hernia $\cdot$ Metabolic alkalosis $\cdot$ Renal failure $\cdot$ Epileptic seizures

\begin{abstract}
Upside-down stomach represents a critical and rare manifestation of hiatal hernias. Here we report on a 60-year-old male patient who was admitted to our hospital with epileptic seizures and dehydration. Laboratory tests revealed severe metabolic alkalosis ( $\mathrm{pH} 7.56)$ with low potassium $(2.7 \mathrm{mmol} / \mathrm{l})$, hypochloremia ( $<60 \mathrm{mmol} / \mathrm{l})$, increased hematocrit $(53 \%)$ and high levels of serum creatinine $(651 \mu \mathrm{mol} / \mathrm{l})$. Based on a history of recurrent vomiting, gastroscopy and computed tomography were performed. Both diagnostics showed an upside-down stomach with signs of incarceration. Upon infusion of sodium chloride $0.9 \%$, acid-base state, electrolyte balance and renal function became improved. Subsequently, the patient was referred to the department of surgery for hiatoplasty with fundoplication. This case report highlights severe metabolic and neurological disorders as unusual and life-threatening complications of an upside-down stomach.
\end{abstract}

\section{Introduction}

Hiatal hernias represent a frequent gastrointestinal disorder caused by herniation of abdominal organs through the esophageal hiatus. The etiology of hiatal hernias is based on three mechanisms: widening of the diaphragmatic hiatus, pulling up of the stomach by esophageal shortening and pushing up of the stomach by increased intraabdominal pressure [1]. Accordingly, there is a high prevalence of hiatal hernias in power athletes and obese people [2,3]. Moreover, familial clusters of hiatal hernias 
have been described, and the prevalence of hiatal hernias is increased in western populations as shown by a comparison of English (49\%) and Singaporean (4\%) patients with dyspepsia who underwent upper endoscopy [4, 5].

Four types of hiatal hernias can be distinguished [6]. Type I or sliding hiatal hernia is the most common type (85-95\%). It is characterized by a partial herniation of the stomach associated with insufficient closure of the esophageal orifice due to a widening of the muscular hiatal tunnel. Type II, III and IV hiatal hernias are variants of a paraesophageal hernia. In opposition to type I hernia, the gastroesophageal junction of type II hernia remains fixed to the preaortic fascia and the median arcuate ligament. However, a defect in the phrenoesophageal membrane allows gastric herniation, and a continuous enlargement of type II hernia leads to intrathoracic placement of the stomach with the pylorus juxtaposed to the gastric cardia, also referred to as upside-down stomach. Type III hernia consists of type I and II elements, and type IV hernia is caused by a large defect in the phrenoesophageal membrane which allows herniation of other abdominal organs such as colon, spleen, pancreas and small intestine. Type I hiatal hernias are often asymptomatic. The most common symptom is heartburn caused by gastroesophageal reflux disease, which can be successfully treated with proton pump inhibitors [7]. By contrast, patients with paraesophageal hernias are at risk of complications such as incarceration, bleeding, strangulation or perforation. Therefore, surgery is recommended for symptomatic paraesophageal hernias [8]. Here we report on the unusual manifestation of an upside-down stomach. We describe in detail clinical findings, diagnostic steps and treatment strategies.

\section{Case Report}

A 60-year-old male patient was admitted to our hospital with epileptic seizures and dehydration. Clinical examination revealed a delirious patient with skin and mucosal dryness. Family members reported on recurrent vomiting. There was no regular medication taken by the patient. Magnetic resonance imaging excluded cerebral bleeding and ischemia. Laboratory tests showed an elevated serum $\mathrm{pH}$ (7.56), increased levels of bicarbonate $(67.5 \mathrm{mmol} / \mathrm{l})$ and unmeasurable base excess representing a metabolic alkalosis which was partially compensated by increased carbon dioxide $(76 \mathrm{~mm} \mathrm{Hg}$ ) (table 1). In addition, potassium $(2.7 \mathrm{mmol} / \mathrm{l})$ and chloride $(<60 \mathrm{mmol} / \mathrm{l})$ were reduced whereas sodium was normal (143 mmol/l). Moreover, elevated levels of hematocrit (53\%) and creatinine $(651 \mu \mathrm{mol} / \mathrm{l})$ confirmed massive dehydration (table 1). To rule out differential diagnosis, serum concentrations of adrenocorticotropic hormone (ACTH), cortisol, renin and aldosterone were determined. While levels of cortisol $(84.3 \mu \mathrm{g} / \mathrm{dl})$, renin $(83.6 \mathrm{pg} / \mathrm{ml})$ and aldosterone $(289 \mathrm{pg} / \mathrm{ml})$ were elevated, ACTH $(32.5 \mathrm{pg} / \mathrm{ml})$ as well as the aldosterone/renin ratio (3.46) were not altered (table 2). This constellation points to an activation of the sympathetic nervous system but does not support endocrinological disorders such as Cushing or Conn syndrome.

Abdominal ultrasound excluded postrenal failure, and an enlarged stomach indicated gastric outlet obstruction (fig. 1). Based on this finding and on persisting dysphagia, gastroscopy was performed. Here $3 \mathrm{l}$ of fluid were removed from the stomach and esophagus. Thereupon we observed a large hiatal hernia with an intrathoracic pylorus and multiple mucosal hemorrhages (fig. 2 ). This result was confirmed by computed tomography, which showed an upside-down stomach in the posterior mediastinum and a hiatal hernia $3.5 \mathrm{~cm}$ in diameter (fig. 3). Moreover the stomach was surrounded by a fluid fringe indicating incipient incarceration. As an additional finding, pulmonary infiltrates in the right inferior lobe indicated aspiration pneumonia.

Taken together, we diagnosed severe hypochloremic metabolic alkalosis and acute prerenal failure which were caused by recurrent vomiting due to an upside-down stomach and triggered epileptic 
seizures. Intravenous application of sodium chloride $0.9 \%$ and potassium improved acid-base state, electrolyte homeostasis and kidney function. Subsequently, the patient was refer red to the department of surgery and hiatoplasty with fundoplication was successfully performed.

\section{Conclusions}

Upside-down stomach represents a critical stage of type II paraesophageal hernia. About one third of patients with a type II hernia develop complications such as intrathoracic incarceration, bleeding, strangulation or perforation [8]. Accordingly, the most common symptoms include thoracoabdominal pain, heartburn, dysphagia, vomiting and signs of gastrointestinal bleeding, but also dyspnea, cough or precordial oppression can result from intrathoracic squeezing effects of paraesophageal herniation [9]. In addition to such common symptoms, the patient described above developed severe systemic disorders including metabolic alkalosis, acute renal failure and epileptic seizures. Recurrent vomiting due to an upside-down stomach resulted in the loss of large amounts of gastric acid which caused metabolic alkalosis and acute prerenal failure. In addition, metabolic imbalance triggered epileptic seizures. As a differential diagnosis the milk-alkali syndrome, gastric hypersecretion or a large excess of adrenocortical hormones need to be considered. The milk-alkali syndrome is caused by a high intake of calcium carbonate triggering hypercalcemia, metabolic alkalosis and acute renal failure [10]. The latter two effects can also occur in patients suffering from short bowel syndrome with gastric hypersecretion [11]. Cushing and Conn syndrome both enhance renal acid excretion and thereby induce metabolic alkalosis. However, the clinical course of disease, the absence of hypertension, hyperglyc emia or calcium dysregulation as well as normal levels of ACTH and aldosterone/renin ratio excluded these differential diagnoses.

Taken together, this case report highlights upside-down stomach as a possible cause of severe systemic disorders including metabolic alkalosis, acute renal failure and epileptic seizures. Furthermore, the course of disease confirms that surgical treatment of symptomatic type II hiatal hernias should be performed to prevent life-threatening complications.

\section{Disclosure Statement}

The authors declare no financial or nonfinancial competing interests. 
Table 1. Laboratory test results from venous blood

\begin{tabular}{llll}
\hline & Normal values & Day of admission & Day after admission \\
\hline $\mathrm{pH}$ & $7.37-7.45$ & $\mathbf{7 . 5 6}$ & $\mathbf{7 . 4 3}$ \\
$\mathrm{pCO}_{2}$ & $32-46 \mathrm{~mm} \mathrm{Hg}$ & $\mathbf{7 6}$ & $\mathbf{8 2}$ \\
$\mathrm{pO}_{2}$ & $71-104 \mathrm{~mm} \mathrm{Hg}$ & 45 & 59 \\
Bicarbonate & $21-26 \mathrm{mmol} / \mathrm{l}$ & $\mathbf{6 7 . 5}$ & $\mathbf{5 4 . 1}$ \\
Base excess & $-2.0-3.0$ & $\mathbf{N M}$ & $\mathbf{2 4 . 1}$ \\
Sodium & $135-145 \mathrm{mmol} / \mathrm{l}$ & 143 & 141 \\
Potassium & $3.5-4.5 \mathrm{mmol} / \mathrm{l}$ & $\mathbf{2 . 7}$ & $\mathbf{3 . 1}$ \\
Chloride & $95-105 \mathrm{mmol} / \mathrm{l}$ & $<\mathbf{6 0}$ & $\mathrm{ND}$ \\
Calcium & $2.1-2.6 \mathrm{mmol} / \mathrm{l}$ & 2.4 & $\mathrm{ND}$ \\
Magnesium & $0.66-0.99 \mathrm{mmol} / \mathrm{l}$ & 1.24 & $\mathbf{5 5 4}$ \\
Creatinine & $62-106 \mu \mathrm{mol} / \mathrm{l}$ & $\mathbf{6 5 1}$ & $\mathbf{6 0 2}$ \\
Creatine kinase & $20-200 \mathrm{U} / \mathrm{l}$ & $\mathbf{1 , 1 9 7}$ & $44 \%$ \\
Hematocrit & $42-50 \%$ & $\mathbf{5 3 \%}$ & \\
\hline
\end{tabular}

Values from venous blood showed metabolic alkalosis ( $\mathrm{pH} 7.56)$ with partial respiratory compensation $\left(\mathrm{pCO}_{2} 76 \mathrm{~mm} \mathrm{Hg}\right)$ as well as reduced levels of potassium $(2.7 \mathrm{mmol} / \mathrm{l})$ and chloride $(<60 \mathrm{mmol} / \mathrm{l})$ indicating loss of gastric acid. High levels of creatinine $(651 \mu \mathrm{mol} / \mathrm{l})$ and hematocrit $(53 \%)$ reflected severe dehydration with acute renal failure. Increased levels of creatine kinase (1,197 U/l) were caused by epileptic seizures. Numbers marked bold highlight pathological values. NM = Not measurable; ND = not determined.

Table 2. Analysis of hormones regulating the acid-base state

\begin{tabular}{lll}
\hline & Normal values & Day after admission \\
\hline ACTH & $7.2-63.3 \mathrm{pg} / \mathrm{ml}$ & 32.5 \\
Cortisol & $2.3-19.4 \mu \mathrm{dl}$ & $\mathbf{8 4 . 3}$ \\
Aldosterone & $10-160 \mathrm{pg} / \mathrm{ml}$ & $\mathbf{2 8 9}$ \\
Renin & $2.9-27.6 \mathrm{pg} / \mathrm{ml}$ & $\mathbf{8 3 . 6}$ \\
Aldosterone/renin ratio & $<50(\mathrm{pg} / \mathrm{ml}) /(\mathrm{pg} / \mathrm{ml})$ & 3.46 \\
\hline
\end{tabular}

Analysis of ACTH, cortisol, renin and aldosterone revealed no evidence for hyperaldosteronism (Conn syndrome) or ACTH-dependent hypercortisolism (Cushing syndrome). Elevated levels of cortisol $(84.3 \mu \mathrm{g} / \mathrm{dl})$, renin $(83.6 \mathrm{pg} / \mathrm{ml})$ and aldosterone $(289 \mathrm{pg} / \mathrm{ml})$ were most probably caused by activation of the sympathetic nervous system in a critically ill patient. Numbers marked bold highlight pathological values. 


\begin{tabular}{r|l|l|l} 
Case Reports in & $\begin{array}{l}\text { Case Rep Gastroenterol 2012;6:452-458 } \\
\text { DOI: 10.1159/000341509 }\end{array}$ & $\begin{array}{l}\text { Published online: } \\
\text { July 10, 2012 }\end{array}$ & $\begin{array}{l}\text { @ 2012 S. Karger AG, Basel } \\
\text { ISSN 1662-0631 } \\
\text { www.karger.com/crg }\end{array}$ \\
\hline
\end{tabular}

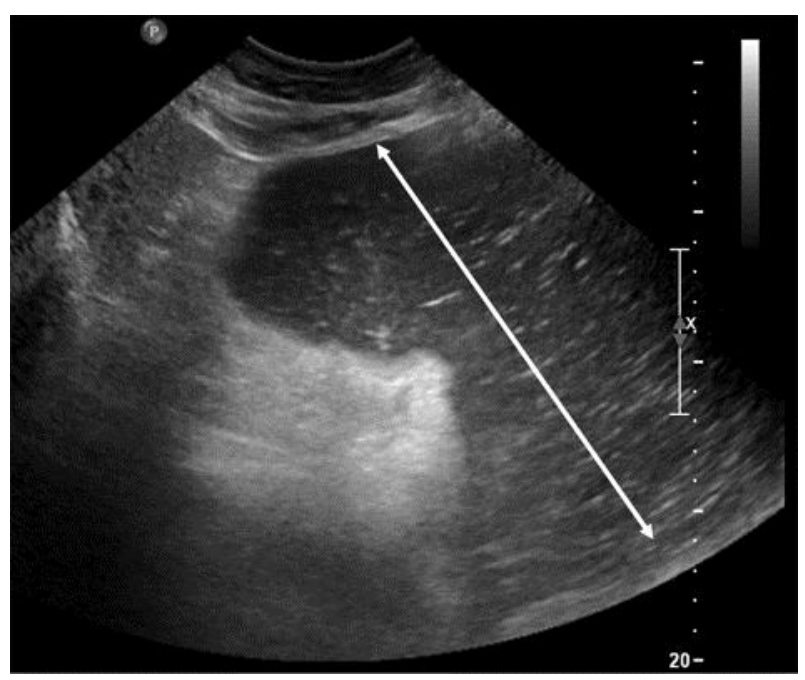

Fig. 1. Abdominal ultrasound showed an enlarged stomach (white arrow) in the subcostal view. Hypo- and hyperechogenic intragastric signals displayed large amounts of fluid indicating gastric outlet obstruction.

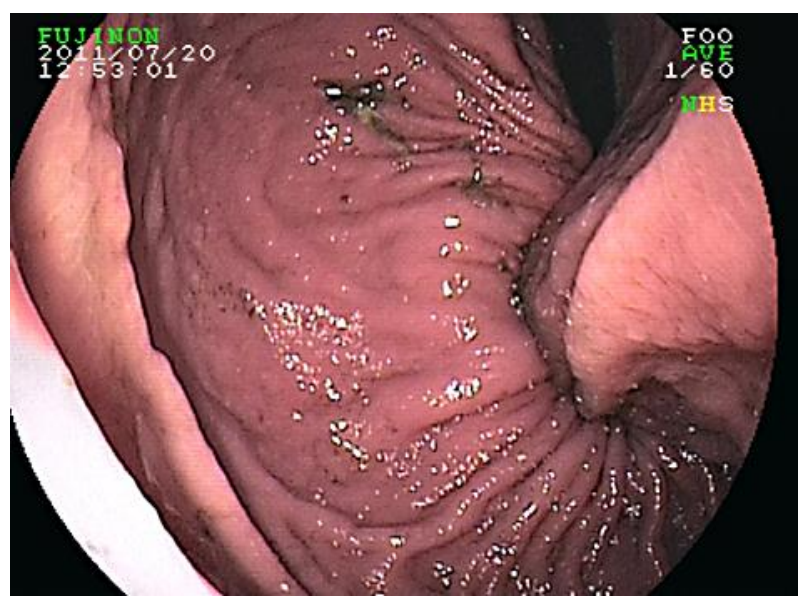

Fig. 2. By esophagogastroduodenoscopy we diagnosed a large hiatal hernia with an intrathoracic pylorus and multiple mucosal hemorrhages as signs of incipient incarceration. The fact that $3 \mathrm{l}$ of fluid were initially removed from the esophagus and stomach confirmed gastric outlet obstruction. 


\begin{tabular}{r|l|l|l}
$\begin{array}{r}\text { Case Reports in } \\
\text { Gastroenterology }\end{array}$ & $\begin{array}{l}\text { Case Rep Gastroenterol 2012;6:452-458 } \\
\text { DOI: 10.1159/000341509 }\end{array}$ & $\begin{array}{l}\text { Published online: } \\
\text { July 10, 2012 }\end{array}$ & $\begin{array}{l}\text { @ 2012 S. Karger AG, Basel } \\
\text { ISSN 1662-0631 } \\
\text { www.karger.com/crg }\end{array}$ \\
\hline
\end{tabular}
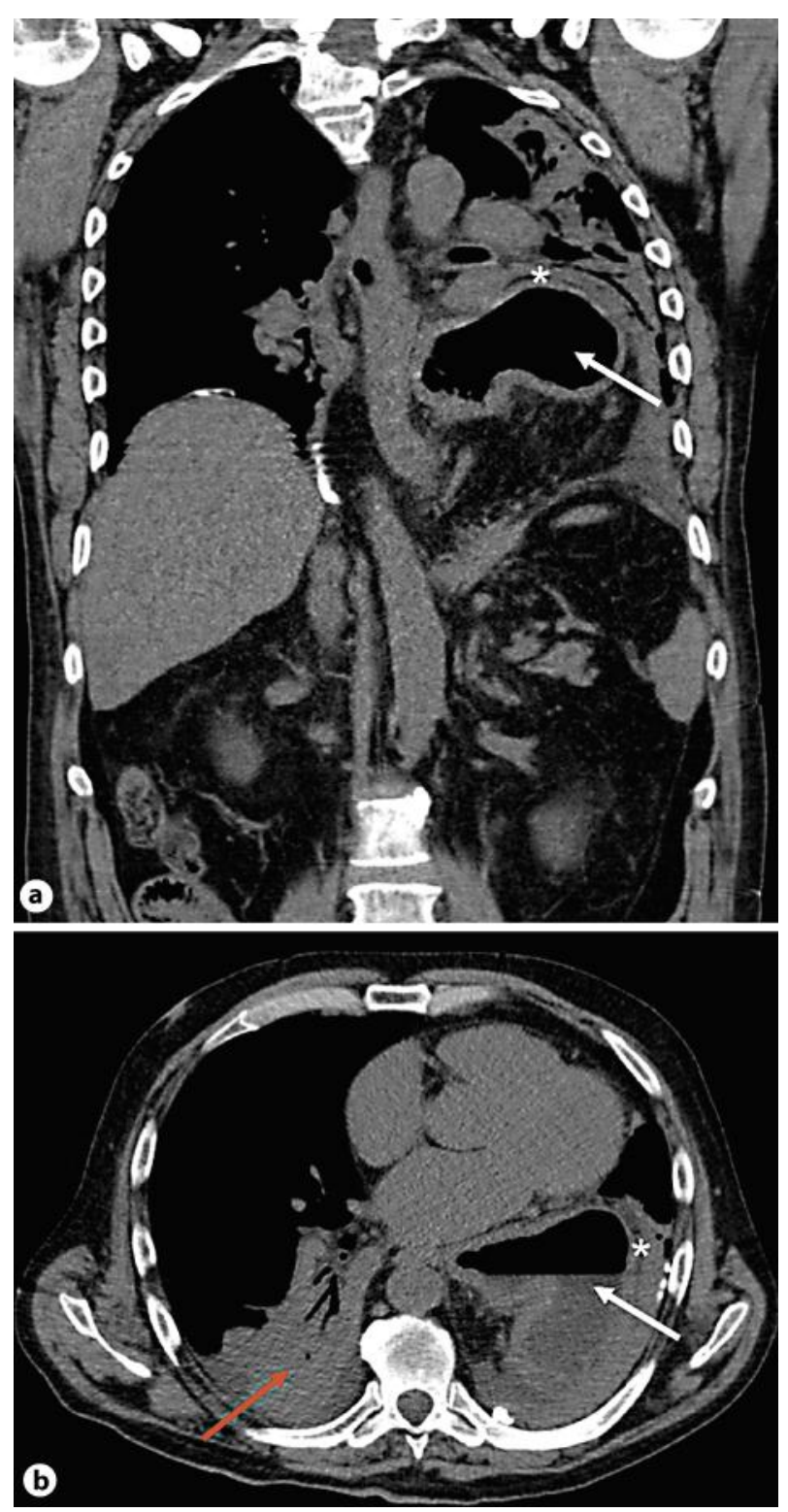

Fig. 3. a Thoracoabdominal computed tomography showed a hiatal hernia $3.5 \mathrm{~cm}$ in diameter and an intrathoracic upside-down stomach (white arrow) surrounded by a fluid fringe (asterisk) as a sign of incarceration. $\mathbf{b}$ In addition, axial projection revealed infiltrates in the right inferior lobe indicating aspiration pneumonia (red arrow). 


\section{References}

1 Gordon C, Kang JY, Neild PJ, Maxwell JD: The role of the hiatus hernia in gastro-oesophageal reflux disease. Aliment Pharmacol Ther 2004;20:719-732.

-2 Smith AB, Dickerman RD, McGuire CS, East JW, McConathy WJ, Pearson HF: Pressure-overload-induced sliding hiatal hernia in power athletes. J Clin Gastroenterol 1999;28:352-354.

-3 Stene-Larsen G, Weberg R, Froyshov Larsen I, Bjortuft O, Hoel B, Berstad A: Relationship of overweight to hiatus hernia and reflux oesophagitis. Scand J Gastroenterol 1988;23:427-432.

-4 Sidd JJ, Gilliam JI, Bushueff BP: Sliding hiatus hernias in identical twins. Br J Radiol 1966;39:703-704.

5 Kang JY, Ho KY: Different prevalences of reflux oesophagitis and hiatus hernia among dys peptic patients in England and Singapore. Eur J Gastroenterol Hepatol 1999;11:845-850.

6 Kahrilas PJ, Kim HC, Pandolfino JE: Approaches to the diagnosis and grading of hiatal hernia. Best Pract Res Clin Gastroenterol 2008;22:601-616.

-7 Peghini PL, Katz PO, Castell DO: Ranitidine controls nocturnal gastric acid breakthrough on omeprazole: a controlled study in normal subjects. Gastroenterology 1998;115:1335-1339.

-8 Horgan S, Pellegrini CA: Surgical treatment of gastroesophageal reflux disease. Surg Clin North Am 1997;77:1063-1082.

-9 Duerst UN, Husmann L, Kaufmann PA: Echocardiographic and 64-multislice computed tomographic manifestation of upside down stomach simulating a compression of the left atrium. Eur Heart J 2009;30: 2896.

10 Jeong JH, Bae EH: Hypercalcemia associated with acute kidney injury and metabolic alkalosis. Electrolyte Blood Press 2010;8:92-94.

11 Jacobi J, Schnellhardt S, Opgenoorth M, Amann KU, Kuttner A, Schmid A, Eckardt KU, Hilgers KF: Severe metabolic alkalosis and recurrent acute on chronic kidney injury in a patient with Crohn's disease. BMC Nephrol 2010;11:6. 